\title{
Intravascular disseminated coagulopathy as a debut of metastatic prostate cancer: A case report
}

\author{
Paula Espinosa Olarte*1, Nerea Inés Muñoz Unceta ${ }^{1}$, Ray Manneh Kopp ${ }^{1}$, Jesús González Olmedo ${ }^{2}$, Daniel Castellano \\ Gauna $^{1}$, Luis Paz-Ares ${ }^{1}$ \\ ${ }^{1}$ Medical Oncology Department, Universitary Hospital 12 de Octubre, Madrid, Spain \\ ${ }^{2}$ Internal Medecine Department, Universitary Hospital 12 de Octubre, Madrid, Spain
}

Received: August 31, 2016

DOI: $10.5430 /$ jst.v7n1p52
Accepted: October 23, $2016 \quad$ Online Published: January 17, 2017

URL: http://dx.doi.org/10.5430/jst.v7n1p52

\begin{abstract}
Hormonal therapy has been the treatment axis of metastatic prostate cancer since 1940. Identifying rare forms of debut is important in order to initiate the best treatment as soon as possible. Intravascular disseminated coagulopathy (DIC) related to prostate cancer is mostly presented as chronic forms. Acute forms can also be the way of presentation, recognizing them is crucial due to its life threatening nature. Here, we present a case of debut of metastatic prostate cancer as an acute DIC. Reporting this case is important because of the unfrequently presentation and to consider combined chemohormonal therapy since the diagnosis.
\end{abstract}

Key Words: Intravascular disseminated coagulopathy, Prostate cancer, Chemohormonal therapy

\section{INTRODUCTION}

Prostate cancer is the most frequent neoplasia in men and the fourth neoplasia in both sexs. An estimate of 1.1 million men worldwide were diagnosed with prostate cancer in 2012..$^{1]}$ In 2016 , it is estimated that 180,890 new patients will be diagnosed with prostate cancer and approximately 26,120 people will die due to this disease in EEUU. ${ }^{[2]}$

The initial treatment of metastatic prostate cancer is based on androgen deprivation therapy ( $\mathrm{ADT}^{[3]}$ ). In 1940 the first regression was described with surgical castration. Luteinizing hormone-releasing hormone (LHRH) analogs showed equivalence in overall survival, progression-related outcomes and time to treatment failure, minimizing psychological effects. LHRH agonists may be administered with anti-androgen therapy to avoid initial testosterone flare.

Docetaxel added to ADT must be considered as an upfront therapy based on the results of two large phase III trials (ECOG 3805/CHAARTED and STAMPEDE).$^{[4,5]}$ These trials showed improvement in overall survival compared to ADT alone (1.1 and 1.8 years respectively).

Multiple coagulation alterations associated with prostate cancer have been described: thrombotic thrombocytopenic purpura (TTP),${ }^{[6-8]}$ thrombosis, ${ }^{[9]}$ hemolytic uremic syndrome (HUS), ${ }^{[8,10]}$ and disseminated intravascular coagulation (DIC). ${ }^{[8,11]}$

Bleeding might be a complication or even the form of debut of metastatic prostate cancer. It is important to accurately establish the underlying coagulation disorder in order to select the best treatment.

Here, we present a case of acute DIC in a patient with prostate cancer. This case highlights the importance of DIC related to prostate cancer or other malignancies as the underlying cause

\footnotetext{
*Correspondence: Paula Espinosa Olarte; Email: paula.espinosa.olarte@ gmail.com; Address: Medical Oncology Department, Universitary Hospital, 12 de Octubre, Avda de Córdoba s/n 28041, Madrid, Spain.
} 
of spontaneous bleeding even in a patient without previous history of cancer. Additionally, it allows for considering new approaches since new treatment strategies have been established in prostate cancer management.

\section{Case presentation}

A 77-years old man with medical history of: Hypertension treated with enalapril, hypercholesterolemia, in treatment with enalapril and statins, and moderate COPD (former smoker IPA 30).

In addition he had a Gleason $7(4+3)$ prostate adenocarcinoma T3bNOMx treated with radical radiotherapy in April 2005, with biochemical recurrence at last check, Prostate-Specific Angiten (PSA) of $3 \mathrm{ng} / \mathrm{dL}$ in march 2015. Prior value in January 2014 was $0.3 \mathrm{ng} / \mathrm{dL}$, pending new PSA determination, CT scan and bone scintigraphy.

In May 2015, the patient consulted our emergency department complaining asthenia, hyporexia, and weight loss of $5 \mathrm{~kg}$ in the last 2 weeks. Physical examination revealed bilateral wheezes, and a low peripheral oxygen saturation (92\%) at rest. Chest radiography did not show abnormality.

Laboratory tests showed mild thrombocytopenia, 90,000 platelets $/ \mu \mathrm{L}(140,000-450,000 / \mu \mathrm{L})$, with the other series preserved, impaired renal function with serum creatinine $2.35 \mathrm{mg} / \mathrm{dL}(0.5-0.9)$ with fractional excretion of sodium (FENa) $0.3 \%$, urinary sediment was normal; DHL 1,247 U/L (135 -214); ALP 224 U/L (35-105), C-reactive protein (CRP)
$3.36 \mathrm{mg} / \mathrm{dL}$ (0.1-0.5). Coagulation tests were preserved.

Previous laboratory tests in March 2015 revealed creatinine $1.16 \mathrm{~g} / \mathrm{dL}$, DHL $171 \mathrm{U} / \mathrm{L}$; haemoglobin $15 \mathrm{~g} / \mathrm{dL}$ (11.4$15.1 \mathrm{~g} / \mathrm{dL})$, leukocytes $7,700 / \mu \mathrm{L}(4,000-11,600 / \mu \mathrm{L})$, platelets $195,000 / \mu \mathrm{L}(140,000-450,000 / \mu \mathrm{L})$.

Due to laboratory abnormalities and the rapid onset of symptoms he was admitted to complete study.

During the first day of admission the patient developed an extensive haematoma in the flexure of right arm related to venipuncture. Without sensorial or motor deficit, it was managed with compression and local measures.

Lab tests showed consumptive coagulopathy prothrombin activity (PA) 63\% (75\%-140\%), prothrombin time (PT) was 15 seconds (8.5-13.8), international normalized ratio (INR) was 1.38 (0.8-1.2), activated partial thromboplastine time (aPTT) was 35.1 seconds (26-39) fibrinogen was low 103 $\mathrm{mg} / \mathrm{dL}$ (200-560 mg/dL) and worsening anemia and thrombocytopenia (Haemoglobin $11.4 \mathrm{~g} / \mathrm{dL}$, Platelets $80,000 / \mu \mathrm{L}$ ).

Despite supportive treatment with fibrinogen and vitamin $k$, the hematoma worsened extending to cervical and dorsal region. He also was oligo-anuric with renal function deterioration (creatinine $3 \mathrm{mg} / \mathrm{dL}$ ) and deepening anemia (hemoglobin $8.3 \mathrm{~g} / \mathrm{dL}$ ).

The coagulation study revealed hipofibrinogenemia with elevated D-dimers, that joined to the anemia and thrombocytopenia described, made the diagnosis of intravascular disseminated coagulopathy.



A

$\mathrm{B}$

Figure 1. Abdominal CT at diagnosis. A) Retroperitoneal and B) external iliac limphadenopaties. 
In the study of the underlying cause of DIC and considering his medical history, PSA serum level was determined, the result was $495.6 \mathrm{ng} / \mathrm{ml}$. In the CT scan he had retroperitoneal, external iliac lymphadenopathies and bone blastic lesions confirmed in the bone scan. (see Figures 1 and 2).

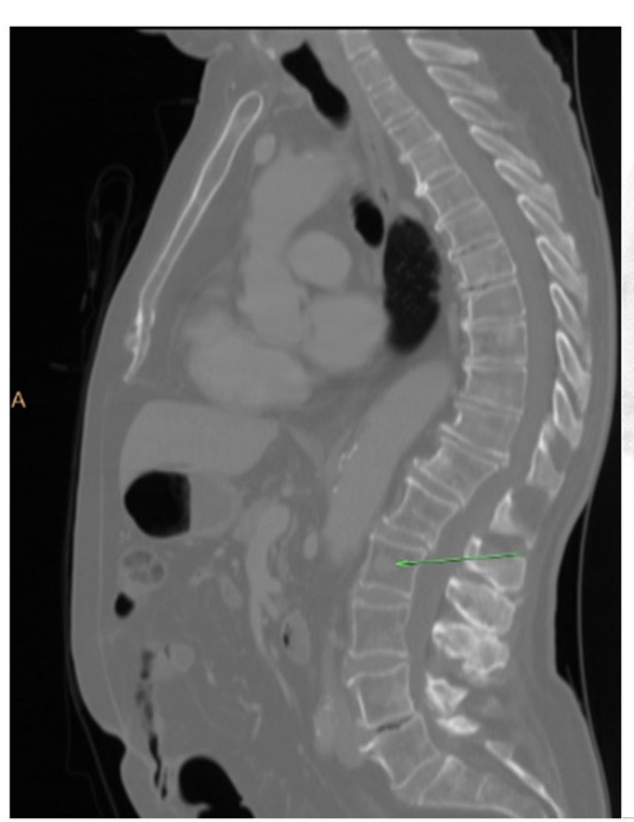

A

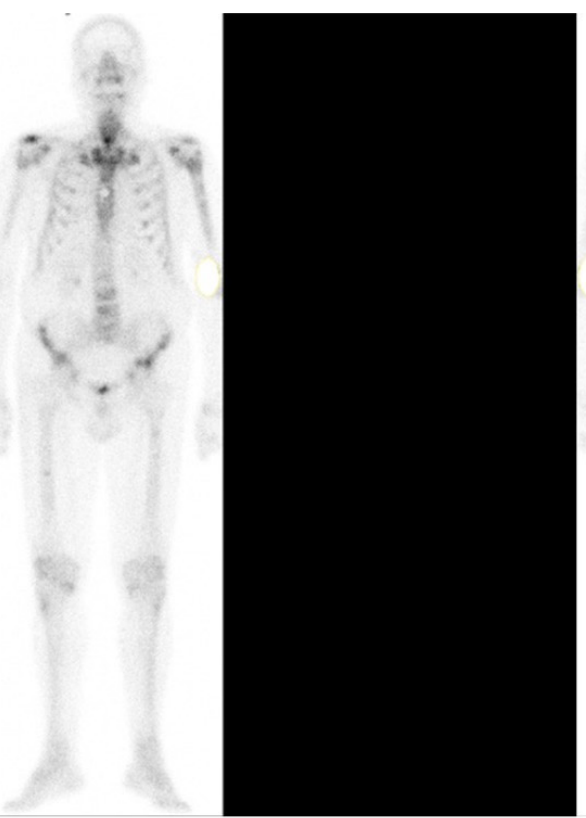

B

Figure 2. A) CT and B) bone scintigrahy showing bone lesions chievly in axial skeleton at diagnosis.

With the diagnosis of DIC related to metastatic prostate cancer, anti-lysis measures with intensive hydratation and allopurinol were instaured. Antiandrogen treatment with bicalutamide was initiated to prevent testosterone flare up derived from LHRH analogues that were administered 10 days later.

Progressively coagulation, renal function and haematological series were recovered.

One month after discharge he had a PSA value of $4 \mathrm{ng} / \mathrm{dl}$ and testosterone in castration range.

After being discussed in prostate cancer comitee and taking into account the aggressiveness of the onset and the metastatic load, we decided to start treatment with docetaxel $75 \mathrm{mg} / \mathrm{m}^{2}$ every 21 days for 6 cycles. He achieved complete response of the lymph node involvement and stability of bone disease with PSA nadir of $0.08 \mathrm{ng} / \mathrm{dL}$ after 4 months. As adverse effects he developed G1 sensitive neuropathy, G1 asthenia and G3 afebrile neutropenia requiring GCSF as secondary prophylaxis.

\section{Discussion}

DIC is a systemic entity that consists in a massive activation of the coagulation pathway due to the exposure to new procoagulant agents released from tumor cells with an associated consumption coagulopathy with decreasing platelets and anticoagulant factors. ${ }^{[12-14]}$ There is an increased fibrinolysis in areas of thrombus formation and release of fibrin degradation products. It generates predisposition to both bleeding and thrombogenesis with potential further organ damage being the kidneys the most frequently affected (25\%-40\%).

It is important to distinguish DIC from primary hyperfibrilolysis where plasminogen activators released from tumor cells convert plasminogen to plasmin which breaks downs fibrin clots. This is the reason of low levels of plasminogen and fibrinogen with elevated fibrin degradation products.

DIC is a dynamic process. Its presentation can be acute with lethal consequences due to the incapacity of hemostasis to replace the increasing consumed coagulation factors and platelets requirements. It could also be chronic or subclinic, mainly manifested as thrombotic events. ${ }^{[14]}$

Acute DIC represents a diagnostic challenge. The identification of the underlying process is crucial for its management. When associated to malignancy it is related with high tumor burden and worse prognosis. As it has potentially lethal consequences, we should consider it in the differential diagnosis in order to initiate supportive therapy and specific antineoplastic treatment as soon as possible. The most fre- 
quently described neoplastic causes are: acute promyelocytic leukemia, pancreas, gastric, breast, ovarian and prostate cancer.

Risk factors for development of DIC in the context of malignancy include: $>60$ years old, male sex, breast cancer, tumor necrosis and advanced stage.

Acute DIC is frequently shown as bleeding which is commonly manifested as ecchymoses, petechiae, bleeding from catheters, and mucosas. The most common laboratory abnormalities most frequently shown in DIC are prolongation of the prothrombin time and the international normalized ratio (PT/INR) and aPTT, hipofibrinogenemia and mild thrombocytopenia (rarely severe). Thrombocytopenia does not appear in primary hyperfibrinolysis.

For its management it is important to treat the underlying cause while offering hemostatic support. ${ }^{[14]}$ In general platelets transfusion are recommended when blood counts are $<50,000 / \mathrm{microL}$ and there is a severe bleeding, or under $10,000 / \mathrm{microL}$ due to the risk of spontaneous bleeding. Blood red cell transfusions are also recommended when secondary anemia appears. Coagulation factors replacement with fresh frozen plasma, cryoprecipitate or fibrinogen are indicated when clotting times are prolonged and fibrinogen low $(<50 \mathrm{mg} / \mathrm{dL})$.
Unlike primary hipofibrinogenemia, antifibrinolytic agents such as tranexamic acid are contraindicated since they can increase thrombotic events.

In the literature, there have been described successful treatments in patients who developed DIC due to prostate cancer with ketoconazole, LHRH analogues and bicalutamide; however, most patients required chemotherapy despite haematological alterations. ${ }^{[8,15,16]}$

Although there is not enough data, these patients probably need chemo-hormonal treatment. Based on the results of two large randomized phase III trials (CHARTED, STAMPEDE) we should consider combination treatment with LHRH analogues and Docetaxel as upfront treatment. ${ }^{[5,6]}$

There is controversy about the moment to iniciate chemotherapy due to the haematological disorders involving DIC, but treating the underlying cause is crucial in the evolution of the coagulopathy. ${ }^{[5,14]}$

In our patient we were in a stage of hormone sensitivity unlike most cases in the literature. The early diagnosis allowed us to start treatment with bicalutamide and LHRH analogues solving DIC and further initiation of chemotherapy.

\section{CONFLICTS OF INTEREST Disclosure}

The authors declare that there is no conflict of interest statement.

\section{REFERENCES}

[1] GLOBOCAN 2012: Prostate cancer estimated Incidence, Mortality and Prevalence Worldwide in 2012. International Agency for Research on cancer. World Health Organitation. Globocan.iarc.fr

[2] American cancer society, cancer statistics center. http://cancer statisticscenter.cancer.org

[3] Huggins C, Hodges CV. Studies on prostatic cancer. I. The effect of castration, of estrogen and of androgen injection on serum phosphatases in metastatic carcinoma of the prostate. Cancer Res. 1941; 1: 293-7.

[4] Sweeney CJ, Chen YH, Carducci M, et al. Chemohormonal Therapy in Metastatic Hormone-Sensitive Prostate Cancer. N Engl J Med. 2015 Aug 20; 373(8): 737-46. PMid:26244877. https: //doi.org/10.1056/NEJMoa1503747

[5] James ND, Sydes MR, Clarke NW, et al. Addition of docetaxel, zolendronic acid, or both to first-line long-term hormone therapy in prostate cancer (STAMPEDE): Survival results from an adaptive,multiarm, multistage, platform randomised controlled trial. Lancet; 2015.

[6] Griffin PT, Jaglal M. Metastatic prostate cancer mimicking thrombotic thrombocytopenic purpura. Blood. 2015 Feb 19; 125(8): 1349. PMid:25853149. https : //doi .org/10.1182/blood-201 4-11-608828

[7] Sobieszczanska M, Tubek S, Poplicha D, et al. Henoch-Schönlein purpura (HSP) and high-dose immunoglobulin treatment in patient with familiar prostatic adenocarcinoma. Hum Vaccin Immunother.
2014; 10(2): 358-9. PMid:24231833. https ://doi.org/10.416 $1 / \mathrm{hv} .27012$

[8] Deme D, Ragánet M, Kalmár K, et al. Metastatic prostate cancer complicated with chronic disseminated intravascular coagulopathy causing acute renal failure, mimicking thrombotic thrombocytopenic purpura and hemolytic uremic syndrome: pathomechanism, differential diagnosis and therapy related to a case. Magy Onkol. 2010 Dec; 54(4): 351-7. PMid:21163766. https ://doi.org/10.1556/ MOnkol.54.2010.4.9

[9] Sack GH Jr, Levin J, Bell WR. Trousseau's syndrome and other manifestations of chronic disseminated coagulopathy in patients with neoplasm: clinical pathophysiologic, and therapeutic features. Medicine (Baltimore). 1977; 56: 1. https://doi.org/10.1097/00005792 $-197756010-00001$

[10] Rullan M, Manrique J, Fernandez LL, et al. Advanced prostate cáncer presented with hemolytic uremic síndrome. Nefrologia. 2016; 36(2): 194-6. PMid:26626999. https://doi.org/10.1016/j. nefro.2015.10.003

[11] Desai M, John B, Evans G, et al. Prostate cancer:beware of disseminated intravascular coagulation. BMJ Case Rep. 2015 Mar 27; 2015.

[12] Gordon SG, Franks JJ, Lewis B. Cancer procoagulant A: a factor X activating procoagulant from malignant tissue. Thromb Res Coagul Fibrinolysis. 1975; 6: 127. https : //doi.org/10.1016/0049-3 848 (75) 90018-3

[13] Gordon SG, Mielicky WP. Cancer procoagulant: a factor X activator tumor marker and growth factor from malignant tissue. Blood Coagul 
Fibrinolysis. 1997; 8: 73. https://doi .org/10.1097/00001721 $-199703000-00001$

[14] Wada H, Thachil J, Di NM, et al. The Scientific Standardization Committee on DIC of the International Society Thrombosis Haemostasis: Guidance for diagnosis and treatment of DIC from harmonization of the recommendations from three guidelines. J Thromb Haemost. 2013; 11: 761-7. PMid:23379279. https://doi.org/10.1111/ jth. 12155
[15] Ong SY, Taverna J, Jokerst C, et al. Prostate Cancer-Associated Disseminated Intravascular Coagulation with Excessive Fibrinolysis Treated with Degarelix. Case reports in Oncological Medicine. 2014; 2015(531): 1-6. http://dx.doi.org/10.1155/2015/212543

[16] Hyman DM, Soff GA, Kampel LJ. Disseminated intra-vascular coagulation with excessive fibrinolysis in prostate cancer: A case series and review of the literature. Oncology. 2011; 81(2): 119-25. PMid:21986538. https://doi.org/10.1159/000331705 